\section{Los asesinos: La abulia y el sacrificio}

\author{
Ricardo Bedoya
}

E n 1956, el joven Andrei Tarkovski, aún alumno de la Escuela de Cine de Moscú, decidió adaptar el relato "Los asesinos", de Ernest Hemingway, para cumplir con un trabajo de estudios. Lo hizo bajo la supervisión de su maestro Mijail Romm y la colaboración de otros estudiantes de la escuela. El mismo Andrei apareció en un pequeño papel secundario. Demás está decir que el relato de Hemingway, publicado por primera vez en 1927, es ejemplar del estilo del escritor norteamericano, y que ya había sido llevado al cine, en 1946, por Robert Siodmak. El resultado fue una notable película negra, llena de atmósfera y misterio, pero infiel al espíritu y a la letra del original literario. ¿Por qué Tarkovski se interesó en ese relato? ¿Qué encontró el joven cineasta en ese texto escueto y preciso, en ese modelo de narración sin retórica ni adornos? ¿Qué lo llevó a elegir ese cuento breve pero intenso, modélico de una tradición narrativa tan ajena a su cultura rusa, tan querida?

Es muy difícil saber las respuestas, sobre todo ahora que Tarkovski ya no está y que no se encuentran en sus textos o entrevistas respuestas concluyentes al respecto. Solo quedan explicaciones insuficientes de compañeros de su época estudiantil, como Alexander Gordon, que no explican las razones de la opción por "Los asesinos".

Por eso, en este texto especulamos con las causas de la elección de "Los asesinos". Este es, pues, un ejercicio 
hipotético, una suma de suposiciones $y$, por eso, caprichoso. Imaginamos aquí los intereses iniciales de un autor a la luz de lo que hizo luego, mirando las raíces de una obra que años más tarde dio frutos maduros e importantes.

Mario Vargas Llosa ha analizado rasgos centrales de la escritura de Hemingway y de su técnica narrativa:

En alguna parte, Ernest Hemingway cuenta que, en sus comienzos literarios, se le ocurrió de pronto, en una historia que estaba escribiendo, suprimir el hecho principal: que su protagonista se ahorcaba. Y dice que, de este modo, descubrió un recurso narrativo que utilizaría con frecuencia en sus futuros cuentos y novelas. En efecto, no sería exagerado decir que las mejores historias de Hemingway están llenas de silencios significativos, datos escamoteados por un astuto narrador que se las arregla para que las informaciones que calla sean sin embargo locuaces y azucen la imaginación del lector, de modo que éste tenga que llenar aquellos blancos de la historia con hipótesis y conjeturas de su propia cosecha.

Llamemos a este procedimiento "el dato escondido" y digamos rápidamente que, aunque Hemingway le dio un uso personal y múltiple (algunas veces, magistral), estuvo lejos de inventarlo, pues es una técnica vieja como la novela y que aparece en todas las historias clásicas (...) ¿Recuerda usted ese cuento magistral, acaso el más célebre de Hemingway, llamado "Los asesinos"?

Lo más importante de la historia es un gran signo de interrogación: ¿Por qué quieren matar al sueco Ole Andreson ese par de forajidos que entran con fusiles de cañones recortados al pequeño restaurante Henry's de esa localidad innominada? ¿Y por qué ese misterioso Ole Andreson, cuando el joven Nick Adams le previene que hay un par de asesinos buscándolo para acabar con él, rehúsa huir o dar parte a la policía y se resigna con fatalismo a su suerte? Nunca lo sabremos. Si queremos una respuesta para estas dos preguntas cruciales de la historia, tenemos que inventárnosla nosotros, los lectores, a partir de los escasos datos que el narrador omnisciente e impersonal nos proporciona: que, antes de avecindarse en el lugar, el sueco Ole Andreson parece haber sido boxeador, en Chicago, donde algo hizo (algo errado, dice él) que selló su suerte. ${ }^{1}$

La explicación de Vargas Llosa alude a una técnica literaria, la del "dato oculto" o "dato escondido" que luce, brillante, en "Los asesinos" de Hemingway.

El joven Tarkovski realizó una adaptación casi literal del texto original. Sabemos, por supuesto, que no existen este tipo de adaptaciones fieles en el cine, puesto que la transposición de

\footnotetext{
1 VARGAS LLOSA, Mario. "El dato escondido". [En línea] http://www.ciudadseva. com/textos/teoria/ vargas1.htm)
} 
cualquier texto de un lenguaje a otro supone ya una ruptura de la literalidad, pero afirmamos que Tarkovski usó la estructura narrativa de Hemingway como un guión original en bruto, ya que en el cuento, a pesar de su laconismo, están marcadas las indicaciones de tiempo, espacios, fisonomía de los personajes y diálogos escuetos. En la película de Andrei Tarkovski esos diálogos están respetados, incluso en su fraseo original, y se mantienen los nombres de los personajes. Solo se suprime la aparición de un personaje secundario - la portera del edificio donde yace el sueco-y, con esa supresión, Tarkovski concentra aún más la tensión dramática y la sensación de encierro que marca el tono del relato.

Sabemos que las películas de Tarkovski nunca están organizadas de acuerdo con una dramaturgia tradicional o previsible. Sin embargo, narran historias. No es errado pensar que el cortometraje de 1956 nació como producto de un ejercicio destinado a aprender los rudimentos de las técnicas narrativas que, más tarde, el realizador de El espejo y Stalker pondría en cuestión. "Los asesinos" sigue una trama que avanza entre diálogos cortos y acerados que escamotean la mención del motivo que permita entender los hechos expuestos, así como evita la explicación final que satisfaga la curiosidad sobre las motivaciones íntimas del pro- tagonista, que espera la muerte con absoluta pasividad. He allí el dato escondido.

Las tramas de las cintas de Tarkovski reposan sobre zonas de sentido opaco y, por eso, nada es conclusivo. Los datos esquivos, las informaciones que no llegan y las claves que nunca obtendremos, articulan su cine. Y no solo se eluden elementos temáticos o argumentales. Los procedimientos formales también escapan, se deslizan, operan por omisión y se llenan de silencios. Su cine muestra solo la parte expuesta del iceberg. Los espectadores intuimos que hay múltiples sentidos que bullen por debajo, pero a los que nunca accederemos. Y es que la cámara se limita a registrar superficies rugosas, paisajes desolados, interiores con pintura descascarada, torrentes que traspasan techos, perros negros sobre charcos, temblores inesperados, territorios infinitos o zonas de profunda opacidad. La cámara no nos conduce a lo cierto ni a la resolución diáfana. Por el contrario, nos guía hacia el centro mismo del misterio.

Como los movimientos panorámicos sin fin preciso de Stalker. Allí, la cámara gira sobre su eje horizontal como si condujera nuestra mirada o atención hacia un elemento relevante o un dato decisivo. Al acabar el recorrido, solo hemos seguido la trayectoria pero sin obtener ningún resultado concreto. 
El misterio impenetrable de la Zona seguirá oculto; el dato escondido es, pues, un elemento estructurante no solo del relato, sino también de la mirada que se mantiene expectante sin avizorar respuestas.

En "Solaris" también encontramos un modo de exposición que suprime causas, así como Hemingway se abstuvo de revelarnos el motivo de la depresión pasiva del "sueco". Marie-Claude Tigoulet lo explica:

Las imágenes del océano anaranjado, azulado, grisáceo, brumoso y turbulento, hay que considerarlas, en nuestra opinión como primeros planos y funcionando como tales: no nos desvelan más que una mínima parte de este misterioso océano, sobre cuyos poderes conocemos muy poco (...) Hay otros cuatro primeros planos que nos parecen importantes y significativos. Nos estorban: ¿cómo interpretarlos? El primero muestra los ojos del Kelvin cuando viaja para llegar a la sección. Nos presenta el efecto antes que la causa: ese viaje que ya adivinamos a través de los planos del cielo estrellado que siguen (...).

La técnica de presentar los efectos antes que las causas fue tal vez la lección que aprendió Tarkovski de Hemingway, junto con la necesidad de narrar callando y procediendo por alusiones.

Es que el cine de Tarkovski es un cine alusivo y elusivo que nunca ofrece explicaciones ni informaciones definiti- vas. Su rechazo tan conocido al montaje intervencionista de la estirpe de Eisenstein lo orienta en esa vía. Tarkovski escribió que el montaje intelectual, ideológico, conceptual o de atracciones y contrastes, resultaba incompatible con la naturaleza del cine, un arte que, según él, no puede organizarse formalmente a partir de una disposición conceptual. Tarkovski pretendía expresar sensaciones y emociones inefables, que están más allá del descubrimiento súbito de un secreto argumental o el dato decisivo de una intriga.

Un ejemplo interesante de la necesidad de conciliar el carácter alusivo del relato con el empleo de un procedimiento cinematográfico distinto al del montaje conceptual e intervencionista, se encuentra en la película Nostalgia. Allí, en una secuencia de notable condensación poética, un personaje recorre un espacio manteniendo encendida la luz de una vela. Lo vemos trajinar el lugar una y otra vez, tratando de conservar el agonizante resplandor.

Lo que interesa allí es el tiempo casi agónico que transcurre ante nuestra expectativa. Durante más de ocho minutos, vemos el gesto de la mano que protege el fuego del viento y los recorridos casi compulsivos. Solo importa la fluencia del tiempo que pasa. Esta acción mínima, de escasísima relevancia dramática desde el punto de vista tradicional, adquiere dentro de la película la dimensión de una prueba últi- 
ma y un acto de supervivencia. El encuadre es dilatado y lo que importa es el ritmo quedo y la trayectoria pausada del movimiento de la cámara. El motivo de esta acción es un dato oculto y su puesta en escena cinematográfica rehúye cualquier explicación. El sentido final nace del gesto sin causa y de la naturaleza alusiva de la toma, que se prolonga sin corte. La acción adquiere un aire ritual y meditativo. El trance espiritual se traduce en una fluencia temporal que repudia los cortes del montaje.

El acto del personaje de Nostalgia resulta, al cabo, tan impenetrable como la espera pasiva del sueco Ole. Y esa dimensión de lo impenetrable está ofrecida por una opción de estilo: al evitar los cortes recurrentes, la mirada del espectador enlaza los términos del encuadre, establece relaciones entre los objetos y personajes que se sitúan allí y marca índices. La duración del encuadre impone la contemplación de lo tangible y nos remite a sentidos que están siempre más allá.

De allí el carácter elíptico del cine de Tarkovski. La elipsis supone el escamoteo de la información que requiere el espectador para seguir algunos incidentes de la trama. "Los asesinos" es un relato claramente elíptico. El diálogo alude a sobreentendidos que no tienen precedentes en el mismo texto; se habla de hechos pasados que nunca sabemos si son reales o su- puestos; se deja el destino del sueco en un final suspensivo. Esa puede ser una de las razones por las que el joven Tarkovski se interesó en el relato de Hemingway y en su técnica de postergación indefinida del hecho final.

El carácter elíptico distingue la adaptación de Tarkovski de las otras dos versiones del cuento de Hemingway que se han realizado hasta hoy. Tanto en la adaptación dirigida por Robert Siodmak, en 1946, como en la versión realizada por Donald Siegel, en 1964, se urde una explicación a la renuencia del sueco y se hurga en el pasado de la historia, es decir en el origen de la tragedia. Es decir, se inventa la biografía criminal del sueco. En ambas películas, "el dato escondido" termina expuesto. Como exige el relato hollywoodense, la información puede estar descolocada, pero solo de modo temporal. La revelación final es ineludible.

Volvamos a Vargas Llosa:

Esos 'datos escondidos' no tienen respuesta dentro del discurso novelesco y el propio lector debe esclarecerlos a partir de las pocas pistas que la novela le ofrece. A esos 'datos escondidos' definitivos, abolidos para siempre de una novela, podemos llamarlos elípticos, para diferenciarlos de los que sólo han sido temporalmente ocultados al lector, desplazados en la cronología novelesca para crear expectativa, suspenso, como ocurre en las novelas policiales, donde sólo al final se descubre al asesino. A esos 'datos escondidos' sólo momentáneos — descolocados- 
podemos llamarlos 'datos escondidos en hipérbaton', figura poética que, como usted recordará, consiste en descolocar una palabra en el verso por razones de eufonía o rima ("Era del año la estación florida..." en vez del orden regular: "Era la estación florida del año...").

En el caso de Los asesinos, de Robert Siodmak, la influencia de "Ciudadano Kane", de Orson Welles, realizada pocos años antes, es evidente. La cinta está estructurada como una encuesta que busca comprender la causa de la muerte de un hombre. A partir de allí se suceden los testimonios y los relatos que tratan de iluminar el pasado, lo que significa obrar con el dato escondido en hipérbaton (el misterio de "rosebud" en la película de Welles tiene la misma naturaleza).

La cinta de Siodmak es muy rica desde el punto de vista estilístico y mitográfico, ya que las presencias de Ava Gardner vestida de negro - apariencia citada por el personaje de $\mathrm{Ca}$ mila (Laura Elena Harring) en El camino de los sueños, de David Lynch- $\mathrm{y}$ Burt Lancaster son impresionantes, pero la narración adolece de un mecanicismo casi fatal que obliga a encontrar la causa última que reacomoda el dato desplazado hasta ese momento.

El fragmento inicial de la película de Siodmak, que corresponde a la adaptación directa del relato de Hemingway, es un triunfo del estilo atmosférico del cine negro. Claroscuros, concentracio- nes atmosféricas, zonas netas de luz y sombra, rostros amenazantes de los asesinos y un Burt Lancaster que yace en estado de gracia, como repitiendo los modelos de la iconografía religiosa del Mesías esperando su destino, son los puntos más fuertes de esta película. En el caso de la cinta de Donald Siegel, que fue el director originalmente previsto para realizar la versión de los años cuarenta, la adaptación de Hemingway se extravía hasta terminar como un pretexto. La secuencia inicial del ingreso de los asesinos se ambienta en una institución para ciegos y no en un bar, y la identidad física de los dos personajes se rompe en beneficio de un Lee Marvin de presencia contundente. La metáfora de los asesinos, cubiertos con anteojos oscuros como ciegos que cumplen su misión sin contemplaciones, funciona muy bien. La película durante todo su desarrollo tiene una dimensión dinámica, de acción física neta y narración vectorial.

Pero no todo se agota en un asunto de técnicas narrativas o especificidades de la adaptación literaria. En "Los asesinos" encontramos motivos que recorren la obra posterior de Tarkovski. Uno de ellos es el del exilio.

Se ha dicho muchas veces que Tarkovski fue un exiliado vocacional. No solo por las condiciones materiales o geográficas de su obra, o por sus relaciones con la administración soviética, sino por ese modo tan particular de 
encarnar la abulia existencial, diseminada en tantos personajes que padecen de incapacidad para actuar de modo voluntario y afirmativo. Ante un mundo de sentidos impenetrables, ellos se mantienen en una actitud de ausencia que a veces se asemeja al desconcierto o luce como ensimismamiento.

La elección del cuento de Hemingway, en 1956, constituyó un modo de afirmación particular. Para ese trabajo estudiantil, Tarkovski no optó por un relato capaz de encarnar las tradiciones de su pueblo ni la ideología oficial vigente. Por el contrario, escogió la obra de un célebre escritor occidental que logró combinar en pocas páginas la concreción de una historia acotada en espacio y tiempo y una dimensión muy curiosa de espiritualidad. Ya a los 24 años, Tarkovski se afirmaba como extranjero a la tradición de lo soviético y su cultura afirmativa y "progresista".

En "Los asesinos", el comportamiento del "sueco", su abulia, su pasividad, su negativa a actuar, llaman la atención, escapan a lo previsible, lucen como una rebeldía interna o como un reclamo final de libertad personal.

El crítico norteamericano Jonathan Rosenbaum ha dicho que en las películas de Tarkovski, un hombre puede afirmar: "soy un prisionero en todo lugar". No importa dónde esté, sea en el gran espacio de la campiña nórdica o en el más bello lugar de la Toscana, los sentimientos de extrañeza y relegación pesan en él. Por eso, el sueco Ole es el primer prisionero interior del cine de Tarkovski. Exiliado de la vida, de la aventura, del mundo del crimen, o de lo que fuere, Ole elige mantenerse en la extrañeza. En un mundo de espacios duales, su zona es la de la habitación en claroscuro. Allí se queda y esperará la muerte. Lo que lo lleva a la memoria del bien perdido (la libertad, la vida misma) y a la melancolía, ese sentimiento que irriga todo el cine de Tarkovski, pero particularmente cintas como Nostalgia y El espejo.

Estar exiliado, o ser prisionero, es vivir con un sentido claro de la impotencia. El sueco de Los asesinos no actúa y siente que su tiempo ya pasó; que su vida anterior le ha atado las manos. Es lo mismo que ocurre con Andrei Rublev, cuando no puede pintar, o con el protagonista de El sacrificio, atribulado con el misterio del fin de la humanidad. En Los asesinos, el sueco, echado en la cama de su habitación, tiene la mirada perdida y la cámara lo muestra en ese estado pasivo y de incertidumbre. Pero la impotencia no solamente alcanza al sueco; también afecta a la pareja de asesinos que entran al bar con todo ímpetu (el travelling que los acompaña en su ingreso apunta una decisión que luego pierde impulso ante la imposibilidad de cumplir la misión a la hora señala- 
da) o al propio Nick Adams, el joven que asiste asombrado a la renuncia final de Ole, y que antecede a personajes similares en las siguientes cintas de Tarkovski. Nick es un mensajero del desastre, ese que sobreviene luego de que alguien ha alertado de la caída. Caída inevitable ya que nadie reacciona para impedirla, a no ser que ocurra un "sacrificio". Encontramos ecos de esa misma actitud en el personaje de Domenico en Nostalgia, incapaz de reaccionar e inmolándose por el fuego; y es acaso ese sentimiento de abulia el que se opone al gesto de lucidez final de El sacrificio. Abulia y sacrificio: polos temáticos de una obra muy rica que empezaron a perfilarse en Los asesinos, un cortometraje estudiantil de 1956. 